\title{
IMPACT OF AIR ENTRAINMENT ON THE MICROSTRUCTURE AND MECHANICAL PERFORMANCE OF HIGH PERFORMANCE MORTAR
}

\author{
Jeroen Dils $^{1}$, Veerle Boel ${ }^{1,2}$, and Geert De Schutter ${ }^{1}$ \\ ${ }^{1}$ Ghent University, Magnel laboratory for Concrete Research, Belgium \\ ${ }^{2}$ Ghent University, Industrial Technology and Construction, Belgium
}

At the Magnel Laboratory for Concrete Research an intensive vacuum mixer which can regulate the air pressure is available. As such the amount of entrapped air in cementitious materials can be varied. The effect of the reduced air content due to vacuum mixing on the rheology and workability was already investigated in previous work. Furthermore, the previous work investigated the influence of entrained air on the rheological properties. The impact of vacuum mixing on the compressive strength and the microstructure of (ultra)high performance mortar is documented elsewhere. However, the impact of air entrainment on high performance mortar has not yet been published. Therefore, this paper will focus on the evolution of the pore structure of air-entrained high performance mortar by using mercury intrusion porosimetry, fluorescence microscopy and air void analysis. This data will enable to verify the pore diameters, often used to explain the evolution of the rheology by the ratio of shear stresses and the surface tension. Furthermore it explains the evolution of the density, the compressive strength and the bending tensile strength.

The air entrainment was varied between $0 \%$ and $2.5 \%$ wt.cement. As a consequence the air content was systematically increased. In case of the air void analyser, the amount of air cavities was increased from $1 \%$ to $14 \%$. From the cumulative air void fraction it was noticed that pores with a diameter of $80 \mu \mathrm{m}$ were dominant in the mortar. From data of the mercury intrusion porosimetry the amount of capillary pores was increased from $7.4 \%$ to $22.2 \%$. The critical diameter at lower percentage of air entrainment was $40 \mathrm{~nm}$, a more continuous curve was obtained for the highest percentages. Furthermore, the amount of pores situated between $10 \mu \mathrm{m}$ and $100 \mu \mathrm{m}$ were limited or not existing. In conclusion, this paper highlights the underestimation of the larger air pores by mercury intrusion porosimetry. Besides this, the decrease in compressive strength and bending tensile strength can be explained by the changes in the pore structure. Finally, it was checked whether the increase in plastic viscosity due to air entrainment was caused by the air bubbles or by the polymer itself.

\section{INTRODUCTION}

High performance self-compacting mortar has the ability to push out air bubbles under its own weight. Consequently, the resistance against freeze-thaw cycles with or without deicing salts can decrease due to the total air content reduction. In order to assure the necessary expansion zones ${ }^{1,2}$ air entraining agents (AEA) are commonly used to increase the amount of stable air bubbles. Depending on the mixture, the workability and rheology decrease or increase by the entrained air bubbles $^{3}$. This will depend on the ratio between the surface tension and the shear stress applied during the test. If the latter can overcome the first, the bubbles will deform and increase the fluidity of the mixture. Besides the influence on the durability and the fresh concrete, air entraining agents also alter the pore structure and the mechanical performance of the mortar. The effect of AEA on these properties is the subject of this paper. The pore structure is examined on two different levels. On the one hand, mercury intrusion porosimetry is used to investigate the capillary porosity, ranging from $10 \mathrm{~nm}$ to $10 \mu \mathrm{m}$. On the other hand air void analysis and fluorescence microscopy is performed to evaluate the larger air bubbles ranging from $0.1 \mathrm{~mm}$ to $1 \mathrm{~mm}^{4}$. Both techniques showed an overlap in their measuring range. Consequently it was possible to compare the techniques critically. Similar as in literature, mercury intrusion porosimetry underestimates the 
amount of larger air bubbles in mortar, due to its measuring principle ${ }^{5}$. Furthermore, the bubbles with a diameter of $80 \mu \mathrm{m}$ increase significantly by the addition of AEA. This confirms the average air bubble size often used in literature to explain the influence of AEA on the workability and rheology ${ }^{3}$. The influence of air entraining agent on the mechanical performance was tested by the compressive and bending tensile strength. In conclusion, a good balance is necessary between the air content necessary for a proper freeze-thaw resistance without changing the mechanical performance drastically.

\section{EXPERIMENTAL WORK}

\subsection{Materials and mix proportion}

The composition of the high performance self-compacting mortar (HP-SCM) tested in this work, can be found in Table 1. The chemical composition of the cement is given in Table 2.

Table 1: Mix proportion of the high performance self-compacting mortar.

\begin{tabular}{lc}
\hline$\left(\mathrm{kg} / \mathrm{m}^{3}\right)$ & HP-SCM \\
\hline & \\
\hline CEM I 52.5N & 519 \\
\hline River Sand 0/4 mm & 1284 \\
\hline Limestone filler & 346 \\
\hline Superplasticizer** & 0.76 \\
\hline Water*** & 202 \\
\hline W/B & 0.400 \\
\hline
\end{tabular}

${ }^{* *}$ percentage solid particles of the cement content;

water compensated for water present in superplasticizer.

Table 2: Chemical composition of cement [\%].

\begin{tabular}{ccccccccc}
\hline & $\mathrm{SiO}_{2}$ & $\mathrm{Al}_{2} \mathrm{O}_{3}$ & $\mathrm{Fe}_{2} \mathrm{O}_{3}$ & $\mathrm{CaO}$ & $\mathrm{MgO}$ & $\mathrm{Na}_{2} \mathrm{O}$ & $\mathrm{K}_{2} \mathrm{O}$ & $\mathrm{SO}_{3}$ \\
\hline CEM I 52.5 N & 18.99 & 5.97 & 4.23 & 62.04 & 0.96 & 0.46 & 0.66 & 3.18 \\
\hline
\end{tabular}

The CEM I $52.5 \mathrm{~N}$ had a d $\mathrm{d}_{50}$ of $16.01 \mu \mathrm{m}$, a Blaine fineness of $3959 \mathrm{~cm}^{2} / \mathrm{g}$ and a density of 3033 $\mathrm{kg} / \mathrm{m}^{3}$. The superplasticizer used in this project was a polycarboxylate ether with a solid content of $35 \%$, a density of $1100 \mathrm{~kg} / \mathrm{m}^{3}$ and a molecular weight of $40000 \mathrm{~g} / \mathrm{mol}$. A limestone filler with a $\mathrm{d}_{50}$ of $7.95 \mu \mathrm{m}$ and a density of $2700 \mathrm{~kg} / \mathrm{m}^{3}$. The particle size distribution of the cement and the filler was determined with a wet laser diffractometer. It was measured in isopropanol after a sonification time of 5 minutes. The stirrer rate was $2000 \mathrm{rpm}$ and the obscuration limits were kept between $12 \%$ and $15 \%$. As aggregate a river sand $0 / 4$ was chosen with a $\mathrm{d}_{50}$ of $680 \mu \mathrm{m}$ and a density of 2650 $\mathrm{kg} / \mathrm{m}^{3}$. The amount of air entraining agent was changed between $0.11 \%$ and $2.5 \% \mathrm{wt}$. cement. Each time the amount of water was compensated for the water in the air entraining agent.

\subsection{Mixing procedure}

The mixing procedure was determined by monitoring the evolution of the slump flow in function of the mixing time. The time corresponding to the maximum workability was taken as the required mixing time ${ }^{6}$. In conclusion, a mixing time of $110 \mathrm{~s}$ at $3.3 \mathrm{~m} / \mathrm{s}$ gave the best results. Before this procedure, the dry materials were mixed during $15 \mathrm{~s}$. In the next $20 \mathrm{~s}$, the water was added at a mixing speed of $1.6 \mathrm{~m} / \mathrm{s}$ and the superplasticizer was manually added to the mixture. In case of an air entraining agent, the amount was premixed with the water. The total procedure was performed in a 5 liter intensive vacuum mixer with inclined mixing pan, Figure 1. 


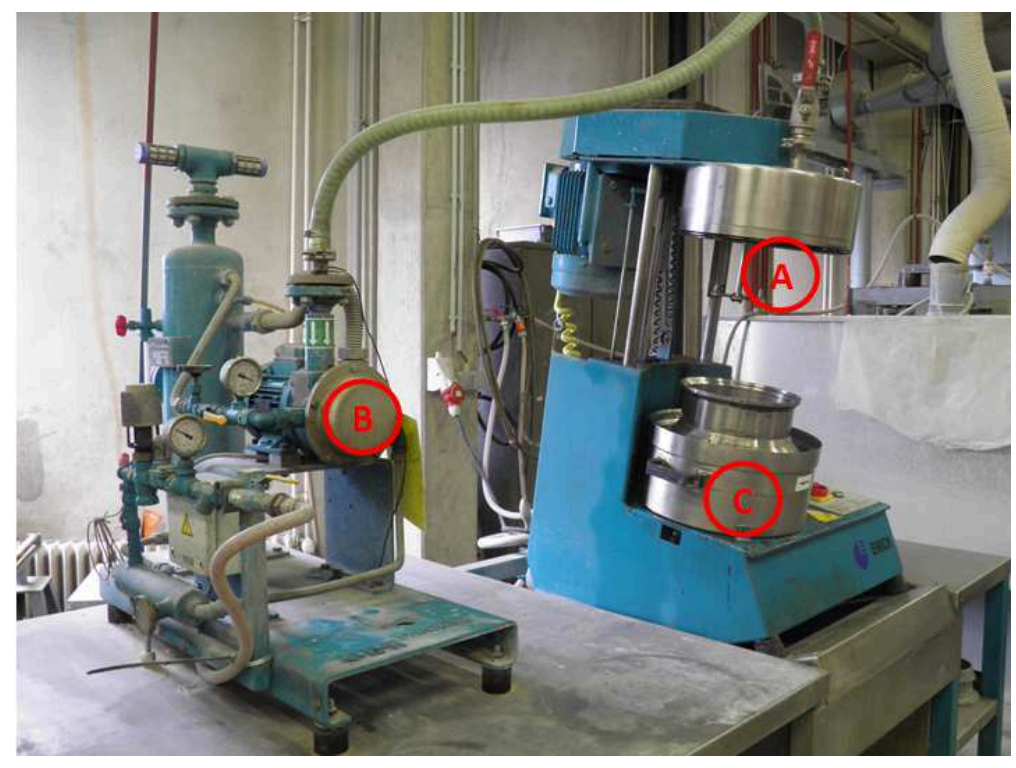

Figure 1: A 5 liter intensive vacuum mixer with inclined mixing pan. A: the pin-agitator; B: the vacuum pump; C: mixing pan and outer protection ring.

\subsection{Methods and sample preparation}

\section{Compressive and bending tensile strength}

The compressive and bending tensile strength was tested according to NBN-EN 196-1 (2005), the prisms $40 \times 40 \times 160 \mathrm{~mm}$ were stored for 2 days in a climate room at $20^{\circ} \mathrm{C} \pm 2{ }^{\circ} \mathrm{C}$ and a relative humidity of $90 \% \pm 5 \%$ before demolding. Thereafter, they were kept under water until the age of testing. After 28 days they were tested in a three point bending machine at a speed of $50 \pm 10 \mathrm{~N} / \mathrm{s}$. In total three prisms were broken in bending. On the five remaining halves a compressive test was performed. One halve was kept aside to examine the pore structure.

\section{Air void analysis}

The air cavities of the hardened mortar were determined by a Rapidair 457 air void analyzer according to the ASTM C457-lineair traverse method. Therefore slices of 40x40x10 mm were made. The preparation of the surface, comprised three phases. First, one side was polished to provide a perfectly planar and smooth surface. Next a binary image was obtained by coloring the surface black with a marker in one direction and filling the voids with a dry white powder $\left(\mathrm{BaSO}_{4}\right)$, having an average particle diameter of $2 \mu \mathrm{m}$. Holes present in aggregates were as a final step painted black with a fine tipped marker pen. The measurement was performed on an area of $25 \times 25$ $\mathrm{mm}$. This area was subdivided in 10 traverse lines to cover a total traverse length of $2413 \mathrm{~mm}$. The measuring range of this technique was $10 \mu \mathrm{m}$ to $3.5 \mathrm{~mm}$. The threshold value was kept constant and based on the experience of the operator. Furthermore the paste content is deduced from the known volumes of components added to the mixer. The result of every sample was an average of four measurements. The sample is turned $90^{\circ} \mathrm{C}$ between individual readings.

\section{Mercury intrusion porosimetry}

The remaining half of the bending tensile test was used to collect debris to determine the capillary porosity with a mercury intrusion porosimeter. No difference in capillary porosity was measured between sawn or broken specimens. For practical reasons, the authors choose broken samples. At the age of 28 days, the debris was collected and hydration was immediately stopped by keeping the specimens in contact with liquid nitrogen for five minutes. Then, they were moved into a freezedryer with temperature of $-24^{\circ} \mathrm{C}$ and vacuum of $0.1 \mathrm{~Pa}^{7}$. After three weeks of freeze-drying the samples were tested. The larger pores, starting from $100 \mu \mathrm{m}$, were determined in a low pressure unit with an increasing pressure from $0.03 \mathrm{kPa}$ to $200 \mathrm{kPa}$. Then, the samples were moved into a high 
pressure unit with a range from $0.1 \mathrm{MPa}$ to $400 \mathrm{MPa}$. The maximum pressure was limited to 200 $\mathrm{MPa}$ to prevent damage to the pore structure. This pressure corresponds to a pore diameter of $0.0073 \mu \mathrm{m}$. The contact angle between the mortar and the mercury was $140^{\circ}$ and the surface tension was taken $0.48 \mathrm{~N} / \mathrm{m}$. Only the pressurization curve was determined, no depressurization was performed. Besides the total capillary porosity and the pore distribution, the critical diameter was also determined.

\section{Fluorescence microscopy}

In order to visualize the effect of air entraining agent on the pore structure of high performance selfcompacting mortar, thin sections were made of the specimens with a different amount of entrained air. The thin sections were impregnated with epoxy which reacts fluorescent under UV-light.

\section{TEST RESULTS AND DISCUSSION}

\subsection{Effect of entrained air on the pore structure of high performance self-compacting mortar}

The effect of air entraining agent on the air cavities was examined by air void analysis, Figure 2 . For each percentage between $0 \%$.wt. and $2.5 \% \mathrm{wt}$. of cement a specimen was prepared for the Rapidair 457. As suspected the hardened air content of the reference mix without AEA was below $2 \%$. The addition of air entraining agent increased the amount of air bubbles up to $14 \%$ of the mortar volume. It is noticed that the mixture with $2.5 \% \mathrm{wt}$. AEA introduced less air than the mixture with $1.25 \%$ wt. For these mixtures, the amounts of small air bubbles become large and it is questionable if the technique is able to measure the amount correctly. At higher percentages of AEA the critical diameter varies around $80 \mu \mathrm{m}$. This diameter corresponds to the steepest slope of the cumulative intrusion curve or in other words with the largest volume increase corresponding to a certain pressurization step. This is in agreement with literature, were a pore diameter of $80 \mu \mathrm{m}$ is often used as a characteristic diameter to interpret the influence of air bubbles on the rheology of self-compacting mortars ${ }^{3}$.

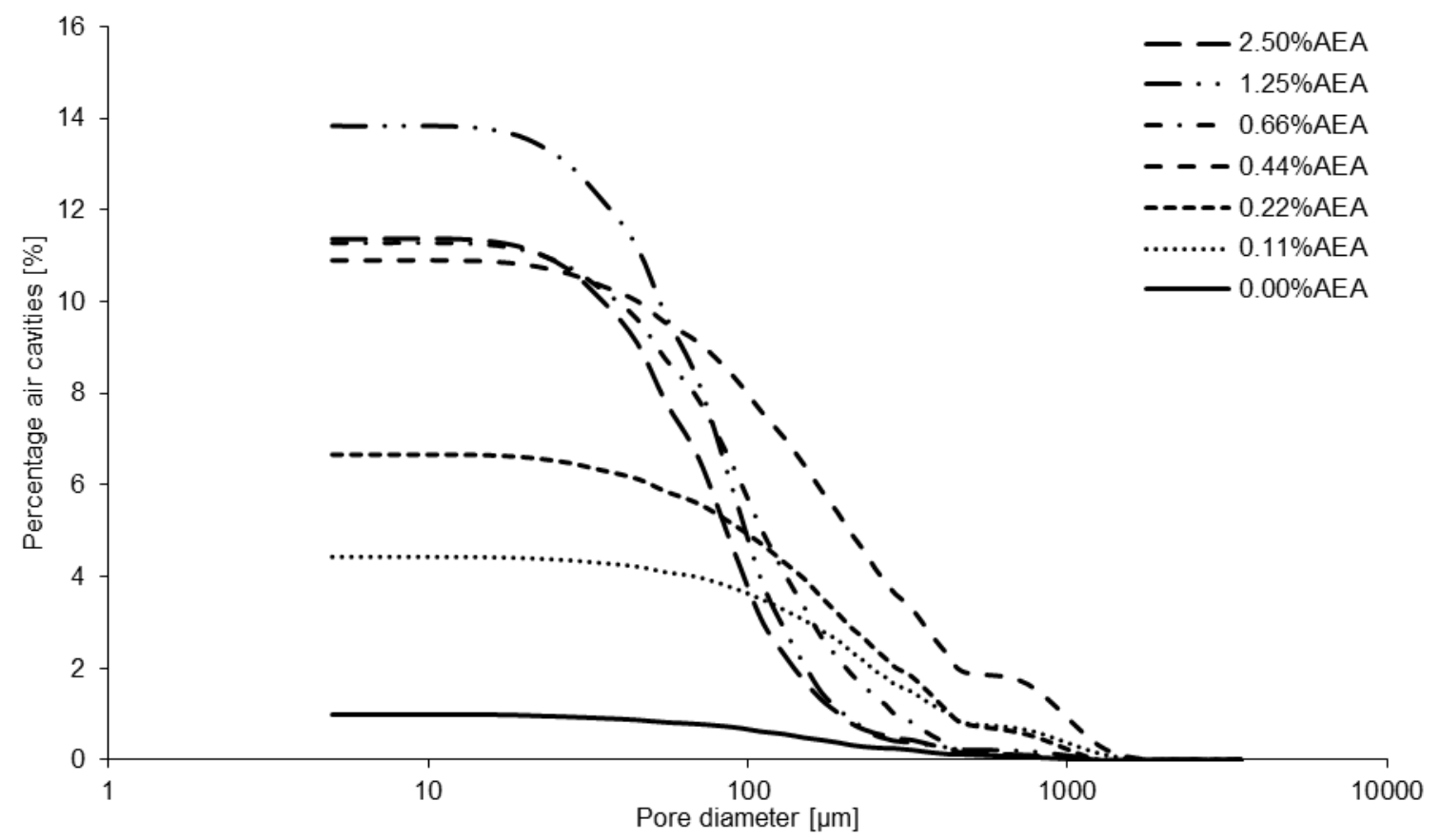

Figure 2: Cumulative intrusion curves of the air cavities in high performance self-compacting mortar made with different percentages of air entraining agents.

From Figure 2 it can be concluded that the air bubbles measured with the Rapidair 457 are situated between $25 \mu \mathrm{m}$ and $1 \mathrm{~mm}$. In order to know the effect on the capillary porosity $(<10 \mu \mathrm{m})$ a different 
test is used. Therefor the different samples were prepared for mercury intrusion porosimetry (MIP), Figure 3. The total porosity of the reference mix without air entraining agent was $7.4 \%$ with a critical diameter of $40 \mathrm{~nm}$. The addition of entrained air bubbles increased the capillary porosity up to $22.2 \%$ for $2.5 \% \mathrm{wt}$. of the cement. The critical diameter stays more or less the same for the different mixtures, however the breakpoint in the curve becomes less clear. The fractions larger than the critical diameter and smaller than $10 \mu \mathrm{m}$ are especially influenced by the addition of air entraining agent. After the critical diameter the slope of the different curves stays the same, indicating the lack of influence of AEA on the corresponding pore diameters. Furthermore, no plateau was reached during the test. This means that there are still smaller pores present in the high performance self-compacting mixtures, namely the gel pores. By comparing both Figure 2 and Figure 3 a discrepancy is noticed. Figure 2 shows a large quantity of air cavities between $500 \mu \mathrm{m}$ and $50 \mu \mathrm{m}$. However mercury intrusion porosimetry does not show any presence of such large pores. According to this technique, the pores are situated between $10 \mu \mathrm{m}$ and $0.01 \mu \mathrm{m}$. This discrepancy was also quoted by Diamond ${ }^{5}$. Here it is stated that the root of the failure of MIP to provide realistic pore size distributions is the assumption that the cylindrical pores are entirely and equally accessible to the outer surface of the specimen ${ }^{5}$. The presence of inkt-bottle pores is one of the reasons why this assumption is not valid. Consequently, the smaller pores are overestimated and the larger pores are not measured properly. Despite the fact that the pore size distribution measured with MIP is unreliable, information on the critical diameter and the total capillary porosity is still valuable information to characterize the influence of air entraining agent on the pore structure of HP-SCM.

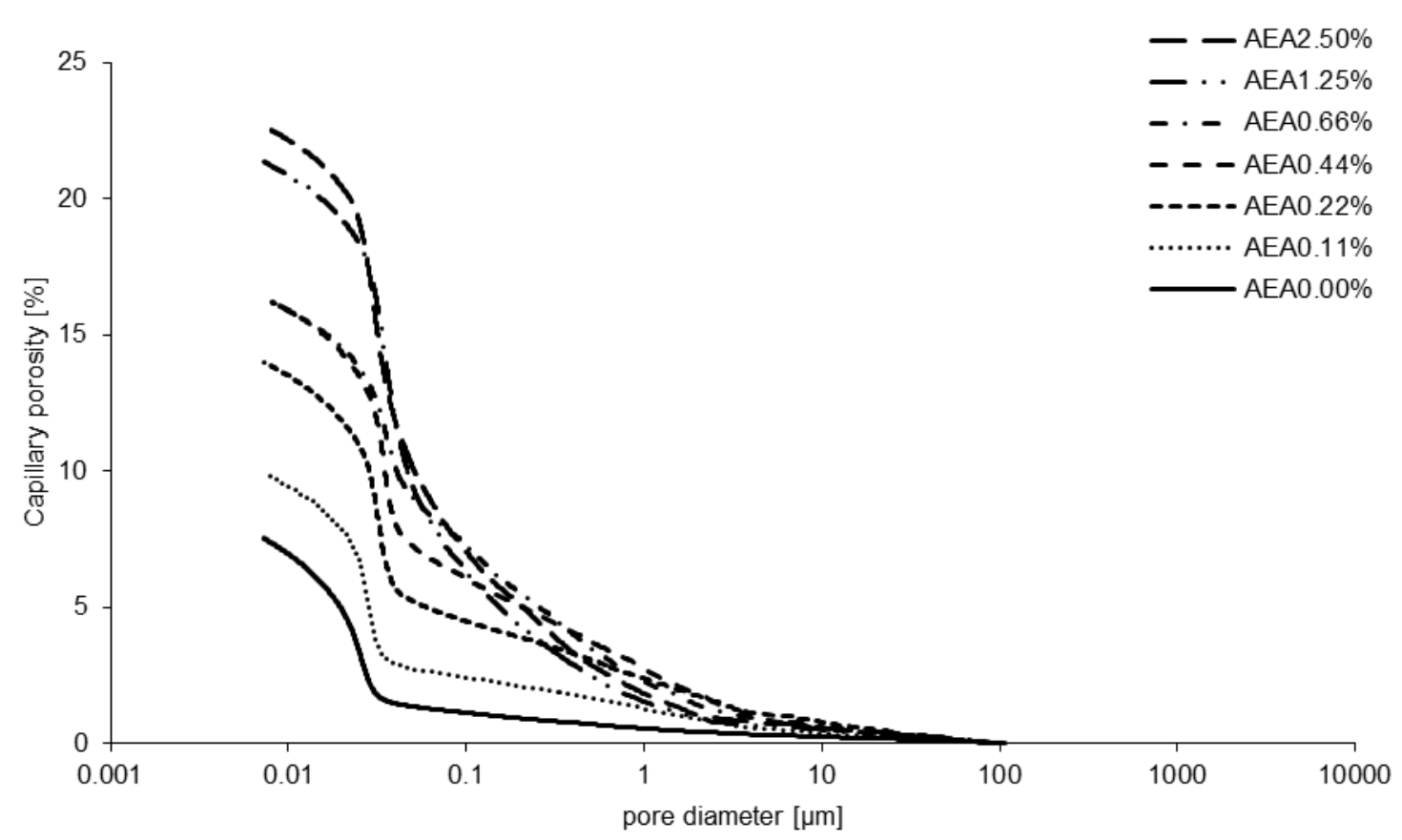

Figure 3: Cumulative intrusion curves of the capillary porosity in high performance self-compacting mortar made with different percentages of air entraining agents.

The presence of larger pores between $500 \mu \mathrm{m}$ and $50 \mu \mathrm{m}$ is double checked with fluorescence microscopy. From Figure 4, it is clearly seen that HP-SCM with $0 \%$ wt. AEA as well with $2.5 \%$ wt. AEA contains pores larger than $50 \mu \mathrm{m}$. This confirms that MIP is an inappropriate measurement technique to determine the pores size distribution of cementitious materials. Furthermore, Figure 4 shows qualitatively the increase of the air content by the use of air entraining agent. Notice, the important increase of the smaller air bubbles. The larger and more irregular pores are presumably entrapped air bubbles, in contrary the smaller and more spherical pores are entrained air bubbles. 


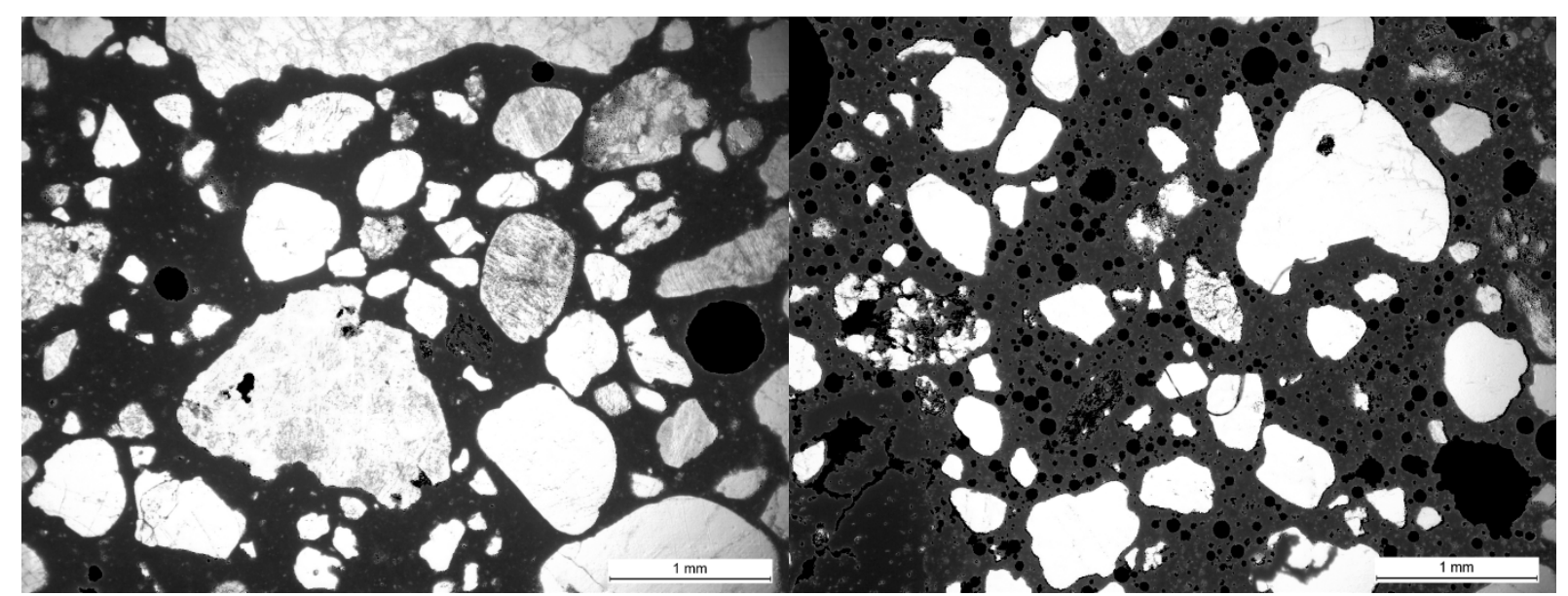

Figure 4: Fluorescence microscopy of a high performance self-compacting mortar with $0 \% \mathrm{wt}$. AEA (left) and with $2.5 \% \mathrm{wt}$. AEA (right). (Pores = black color)

\subsection{Effect of entrained air on the mechanical performance of high performance self- compacting mortar}

In $\$ 2.1$ it is demonstrated that the pore structure of HP-SCM is changed by the addition of air entraining agent. This will have an influence on the mechanical performance of the mortar ${ }^{4}$. From Figure 5 it can be concluded that the reference mix is a high performance mortar with a compressive strength of $90 \mathrm{MPa}$. By increasing the amount of air entrainment up to $2.5 \% \mathrm{wt}$. cement, the compressive strength is halved to $45 \mathrm{MPa}$. The same conclusion can be drawn for the bending tensile strength. The reference mix had a strength of $11 \mathrm{MPa}$, which dropped to $7 \mathrm{MPa}$ at the highest dosage of AEA. In conclusion, the designer will have to look for a balanced amount of entrained air bubbles. In such a way that a good freeze-thaw resistance is obtained without decreasing the mechanical performance of the mortar.
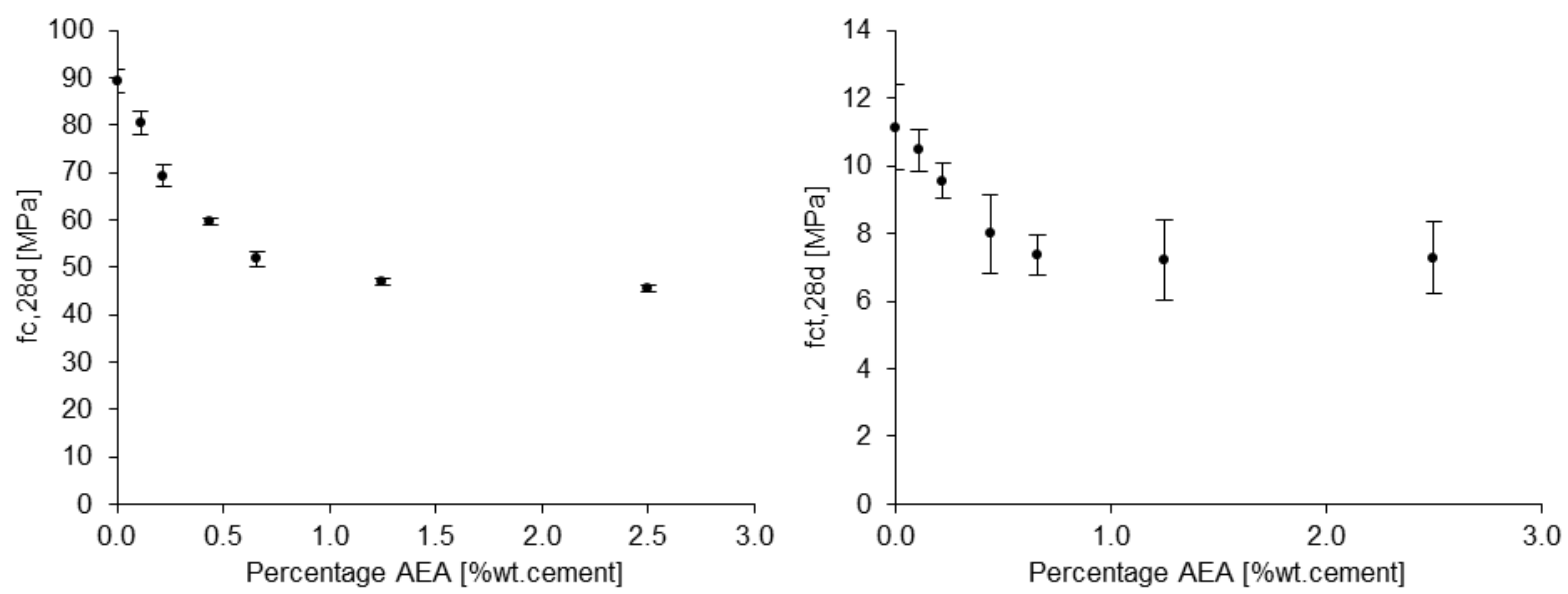

Figure 5: Influence of air entraining agent on the compressive strength (left) and the bending tensile strength (right) on a high performance self-compacting mortar.

\subsection{Effect of entrained air on the rheology of high performance self-compacting mortar}

Finally, the influence of entrained air bubbles on the plastic viscosity according to the modified Bingham model is determined ${ }^{8}$. Apparently the entrained air bubbles are not deformable under the applied shear stress and act as obstacles increasing the plastic viscosity of the high performance self-compacting mortar ${ }^{3}$. Next, it is checked whether the air bubbles or the polymer itself are responsible for the increase in viscosity. 


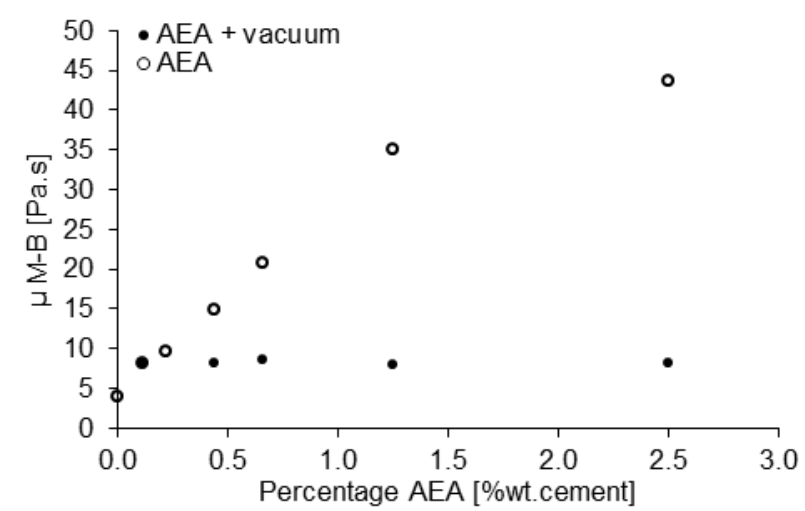

Figure 6: Impact of vacuum mixing on the effect of air entraining agent on the plastic viscosity of high performance self-compacting mortar.

For this, some mixtures were produced at a lower air pressure, namely 50 mbar instead of 1013 mbar. Consequently, the air bubbles were unable to form and only the polymer could affect the plastic viscosity. From Figure 6, it can be concluded that the air bubbles are responsible for the higher viscosity and thus the decrease in fluidity.

\section{CONCLUSION}

In this paper the effect of air entrainment on the pore structure and the mechanical performance of a high performance self-compacting mortar is examined. Besides this the effect of entrained air bubbles on the plastic viscosity is checked. From this investigation, the following remarks can be made:

- Air entrainment increases the amount of air bubbles from $40 \mathrm{~nm}$ up to $1 \mathrm{~mm}$ and thereby changes the mechanical performance of the mortar.

- A discrepancy was noticed between the results of the air void analysis and those from the mercury intrusion porosimetry. It is concluded that the latter is an inappropriate technique to determine the pore size distribution of cementitious materials.

- The plastic viscosity of the high performance self-compacting mortar, used in this study, is increased by the air entrainment agent. It was demonstrated that the air bubbles and not the polymer itself were responsible for this increase.

\section{ACKNOWLEDGMENTS}

The financial support of the Hercules Foundation and of the Fund for Scientific Research Flanders is greatly acknowledged.

\section{REFERENCES}

[1]. Setzer M.J., 'Development of the micro-ice-lens model', International RILEM Workshop on Frost Resistance of Concrete, 2002, 133-145.

[2]. Chatterji S., 'Freezing of air-entrained cement-based materials and specific actions of airentraining agents', Cement \& Concrete Composites, 25 (2003) 759-765.

[3]. Hot J. and Roussel N., 'Fluidifying effect of air entraining agents (AEA)', Proceedings of the 7th RILEM Conference on Self-Compacting Concrete, Paris, 2-4 September 2013, 1-7.

[4]. Mindess S., Young J.F., Darwin D., Concrete, $2^{\text {nd }}$ Edition, Prentice Hall, Englewood Cliffs, NJ, 2002.

[5]. Diamond S., ' Mercury porosimetry an inappropriate method for the measurement of pore size distribution in cement-based materials', Cement and Concrete Research, 30 (2000) 1517-1525. 
[6]. Dils J., De Schutter G. and Boel V., 'Influence of mixing procedure and mixer type on fresh and hardened properties of concrete: a review', Materials and Structures, 45 (2012) 1673-1683.

[7]. Zhou J., Ye G. and Van Breugel K., 'Characterization of pore structure in cement-based materials using pressurization-depressurization cycling mercury intrusion porosimetry (PDCMIP)', Cement and Concrete Research, 40 (2010) 1120-1128.

[8]. Feys D., Verhoeven R., et al., 'Fresh self-compacting concrete, a shear thickening material', Cement and Concrete Research, 38 (2008) 920-929. 